\title{
Advanced approaches to produce polyhydroxyalkanoate (PHA) biopolyesters in a sustainable and economic fashion
}

\author{
Martin Koller ${ }^{1,2 *}$ and Gerhart Braunegg ${ }^{2}$
}

\begin{abstract}
Polyhydroxyalkanoates (PHA), the only group of "bioplastics" sensu stricto, are accumulated by various prokaryotes as intracellular "carbonosomes". When exposed to exogenous stress or starvation, presence of these microbial polyoxoesters of hydroxyalkanoates assists microbes to survive.

"Bioplastics" such as PHA must be competitive with petrochemically manufactured plastics both in terms of material quality and manufacturing economics. Cost-effectiveness calculations clearly show that PHA production costs, in addition to bioreactor equipment and downstream technology, are mainly due to raw material costs. The reason for this is PHA production on an industrial scale currently relying on expensive, nutritionally relevant " 1 st-generation feedstocks", such as like glucose, starch or edible oils. As a way out, carbon-rich industrial waste streams (" 2 nd-generation feedstocks") can be used that are not in competition with the supply of food; this strategy not only reduces PHA production costs, but can also make a significant contribution to safeguarding food supplies in various disadvantaged parts of the world. This approach increases the economics of PHA production, improves the sustainability of the entire lifecycle of these materials, and makes them unassailable from an ethical perspective.

In this context, our EU-funded projects ANIMPOL and WHEYPOL, carried out by collaborative consortia of academic and industrial partners, successfully developed PHA production processes, which resort to waste streams amply available in Europe. As real $2^{\text {nd }}$-generation feedstocks", waste lipids and crude glycerol from animal-processing and biodiesel industry, and surplus whey from dairy and cheese making industry were used in these processes. Cost estimations made by our project partners determine PHA production prices below $3 €$ (WHEYPOL) and even less than $2 €$ (ANIMPOL), respectively, per kg; these values already reach the benchmark of economic feasibility.

The presented studies clearly show that the use of selected high-carbon waste streams of (agro)industrial origin contributes significantly to the cost-effectiveness and sustainability of PHA biopolyester production on an industrial scale.
\end{abstract}

Keywords: Animal-processing industry, biodiesel, biopolyesters, biopolymers, polyhydroxyalkanoates (PHA), raw materials; sustainability, waste streams, whey

'University of Graz, Institute of Chemistry, NAWI Graz, Austria

${ }^{2}$ ARENA (Association for Resource Efficient and Sustainable Technologies), Graz, Austria

*Corresponding author: M. Koller E-mail: martin.koller@uni-graz.at

DOI: 10.2478/ebtj-2018-0013

(C) 2018 Authors. This work was licensed under the Creative Commons AttributionNonCommercial-NoDerivs 3.0 License.

\section{Introduction}

\section{The current global plastic situation}

Nowadays, we are dealing with plastics in many situations of our all-day life; in most cases, "plastics" are polymers stemming from petro-chemistry. Based on favorable material features such as low density, high resistance, and well-optimized manufacturing processes, plastics are by far the fastest emerging group of materials used for manufacturing of customized items. In this context, plastics are needed for packaging of diverse goods, agriculture, electronics, construction industry, transportation, health care, or the sport and leisure sector. However, based on the limitation of petrochemical resources and the recalcitrance of plastics towards biodegradation, we currently observe growing global concern related to traditional plastics of petrochemical origin. Reliable estimates speak about a pile of 8 to $9 \times 10^{9}$ t of plastics that have been made globally in recent decades (1). In the 


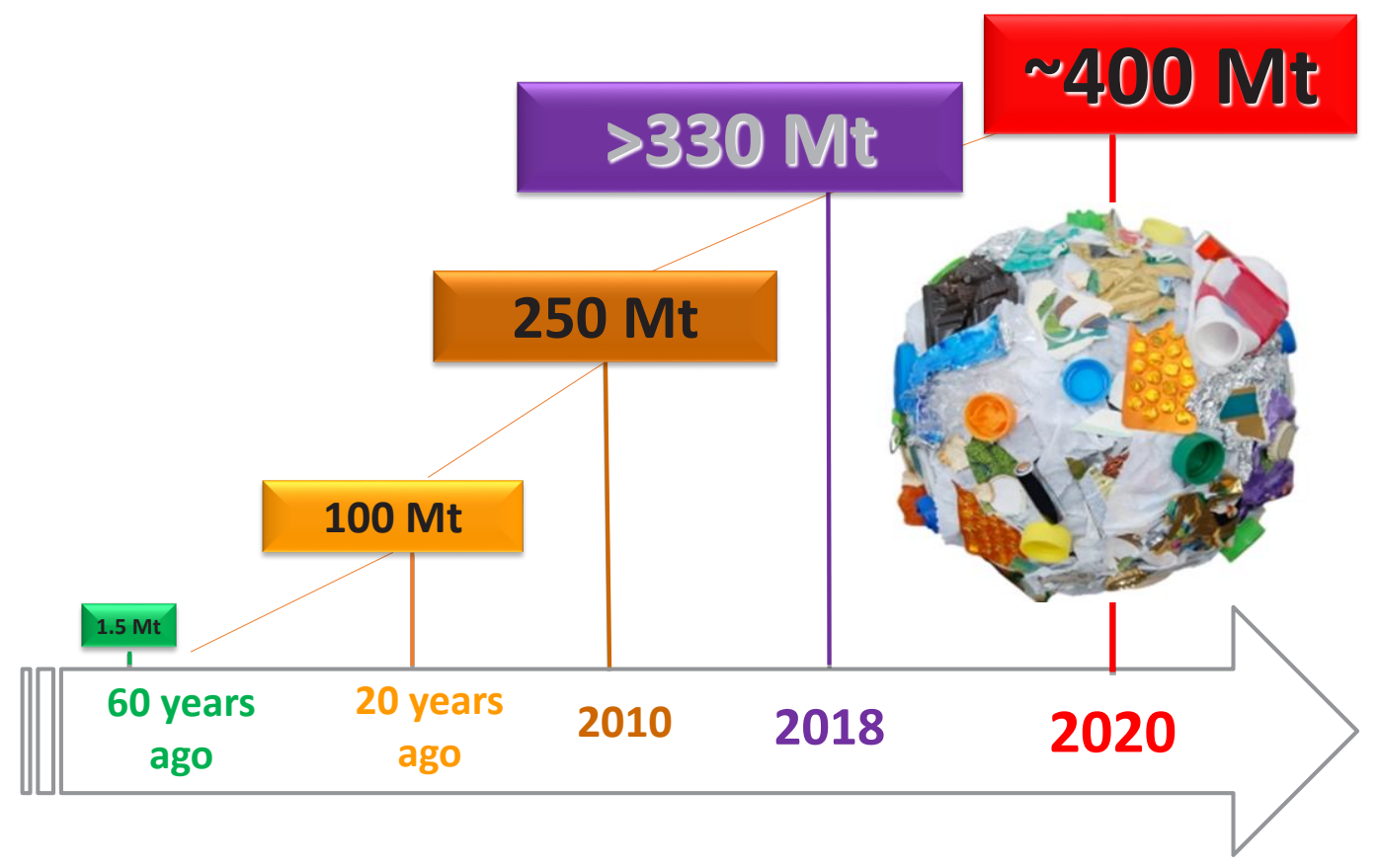

Figure 1. The rising amounts of global plastic production.

face of a current worldwide plastic production of almost $4 \times 10^{8} \mathrm{t}$ annually with an enormous uptrend noticed especially in emerging and developing countries, which are characterized by boosting industrialization (2), it becomes clear that the enormous quantities of spent plastics (already surpassing $15 \times 10^{7} \mathrm{t}$ annually) urgently require proper disposal (3). Fig. 1 illustrates the rising amounts of plastics produced on our planet during the recent decades.

Because of the high recalcitrance of plastics towards (bio)degradation, other methods of disposal are frequently used, often simple landfilling, or they are even just deposited in the environment; this fate struck about $79 \%$ of the total amount of plastic ever produced, and resulted in growing piles of plastic waste and plastic waste distribute all over the planet (2). A currently hot topic is the disastrous pollution of the oceans, the origin of all life, by an approximate amount of $2 \times 10^{6} \mathrm{t}$ of plastic waste entering marine environments mainly via rivers and coastal sewers; as one of the consequences thereof, "microplastics" endanger the complete food chain (4). Alternatively, estimated $12 \%$ of all plastics produced to date were incinerated for energy generation, leading to formation and release of greenhouse relevant and toxic gaseous emissions (1). Alternatively, recycling of spent petrochemical plastics is a generally accepted technology and regarded as "green" and progressive; however, plastic recycling only works to a restricted degree because of the need for a certain purity of spent plastic regarding types of plastics and pollutions, and the material fatigue and quality loss with every recycling cycle $(3,5)$.

\section{Polyhydroxyalkanoates (PHA) - a biological alternative}

As a biological alternative to petrochemical plastics, one can fall back on solutions provided by Mother Nature. In this context, microbially synthesized polyhydroxyalkanoate (PHA) biopolyesters are these days in the focus of microbiologists, systems and synthetic biologists, material scientists, and chemical engineers. This is easily understood due to their beneficial properties such as biodegradability and versatility; these features make them attractive for numerous applications as known for traditional plastics $(6,7)$. PHA were first observed and described almost one century ago by Maurice Lemoigne as light-refractive inclusion bodies in the Gram-positive bacterium Bacillus megaterium (8). Today, it is getting better understood that presence of PHA in living prokaryotic microbes (bacteria or haloarchaea) serves the cells as protection against starvation and various other stress factors, whose connection with PHA biosynthesis was discovered only recently (9). Such challenging stress factors are, e.g., oxidative stress $(10,11)$, high salt load (hypersalinity) (12), UV-irradiation (13), heat (11), or freezing (14). Typically, PHA biosynthesis is favored by limiting a nutrient component essential for microbial growth, e.g., metabolizeable nitrogen compounds, phosphate, or oxygen, with concomitant plentiful availability of exogenous carbon source. Primarily the price of carbon sources needed for PHA biosynthesis, which are often compounds relevant to human nutrition, defines the final production price of PHA; consequently, alternatives must be developed for largescale PHA production (6).

To address the use of inexpensive carbon sources, biorefinery concepts are developed these days, which resort to carbon-rich side streams of diverse (agro)industrial processes to be used as " $2^{\text {nd }}$-generation feedstocks" for PHA production $(15,16)$. In this context, as the first core topic of this review, lactose-rich surplus whey from dairy industry is another viable feedstock for PHA production (17). Further biorefinery concepts are based on PHA production from waste lignocelluloses, such as bagasse, forestry residues, or straw (18), side streams from sugar mills (19), paper industry waste (20), urban sewage (21), nutrient-rich effluents 


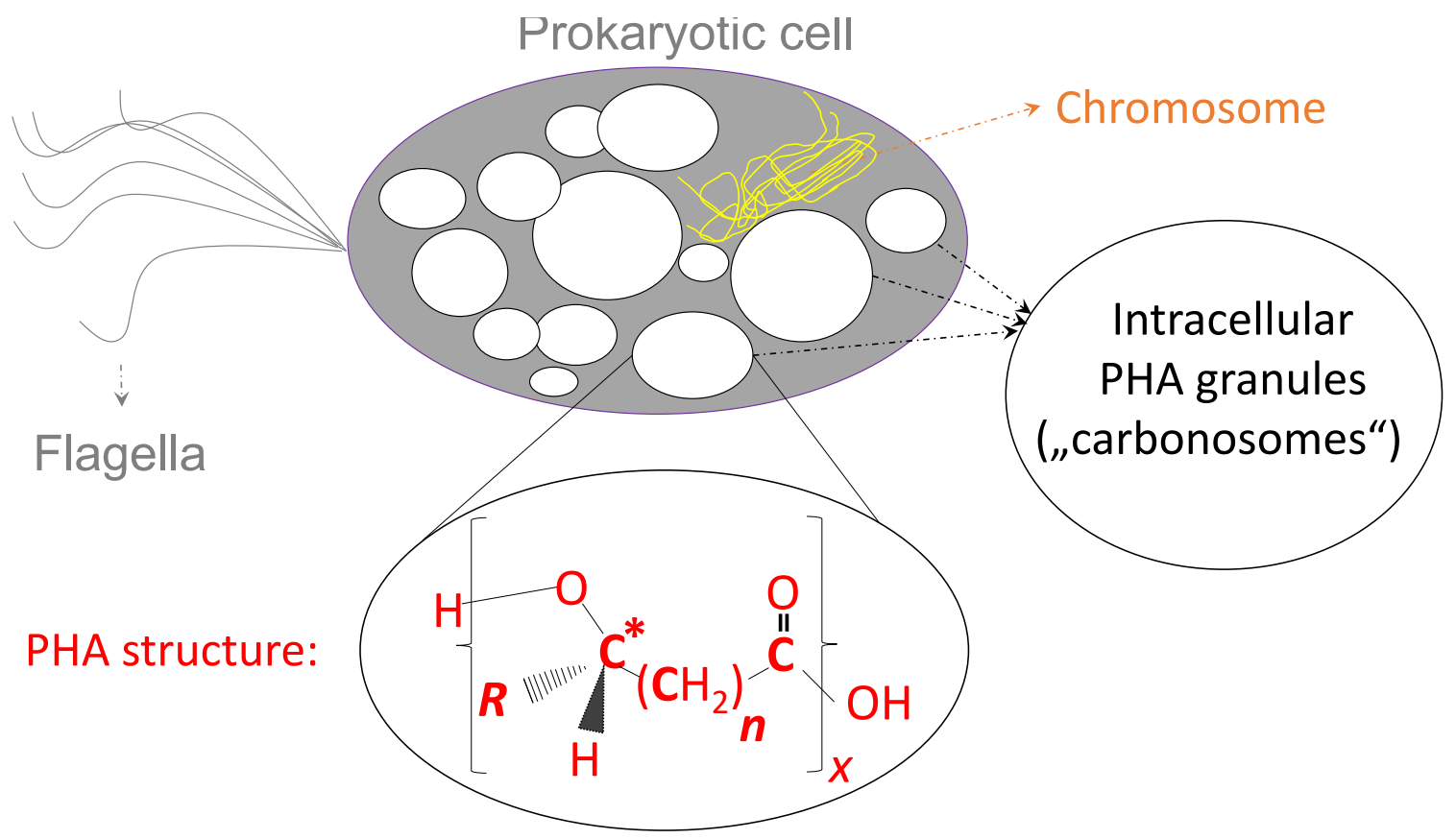

Figure 2. General chemical structure of PHA biopolyesters.

Upper part: scheme of a prokaryotic cell harboring PHA granules ("carbonosomes"). $\boldsymbol{R}$ : side chain of monomers; $\boldsymbol{n}$ : number of methylene groups in backbone of monomers; $\boldsymbol{x}$ : degree of polymerization; *: chiral carbon atom in most PHA building blocks.

of olive oil production (22), or, in the case of autotrophic PHA production strains, carbon dioxide-rich exhaust gases stemming from power plants (23). Moreover, connecting PHA production to the animal-processing industry was accomplished; here, PHA-producing microbes were supplied with low quality biodiesel obtained by transesterification of high-fat animal waste in addition to crude glycerol and innards, which are additional waste streams from this industrial process, as detailed as the second core topic of this review (24).

In addition to the raw material issue, the downstream processing technology for the efficient and sustainable isolation of biopolyesters from microbial biomass, a crucial step in the PHA production chain, is currently under discussion. In this context, PHA extraction by solvent-based techniques, and various methods for chemical, enzymatic, and mechanical disintegration of the non-PHA ("residual") biomass are comprehensively summarized in the current literature. However, all these methods have certain disadvantages either from an economic point of view, for ecological considerations, safety aspects, low PHA recovery yield, product pureness, or because of scaling difficulties, which are industrially critical indeed (25-27). Recent developments to optimize PHA recovery involve the application of harmless solvents (28), supercritical fluids (29), or ionic liquids (30). As a new curiosity which, nevertheless, might have some potential for application, PHA granules of surprising purity can be excreted by some animals like the meal worm Tenebrio molitor, which selectively digest the non-PHA fraction if they are fed with PHArich bacterial biomass (31).

At present, robust microbial PHA producers with well-studied genome and enzymatic machinery, and a broad spectrum of inexpensive substrates utilized by them are in the spotlight of
PHA researchers focusing on microbiological and genetic aspects. Especially exploration of extremophilic microbial strains settling in challenging environments, such as halophile microbes isolated from salt lakes, saltworks, or marine waters, is strongly increasing these days. Application of such production strains enables designing simple, flexible and robust cultivation processes, which can be energy-saving due to low or even without any sterility requirements (32-35).

From the perspective of the chemist, PHAs are polyoxoesters of hydroxyalkanoic acids. To date, a huge number of PHA homoand heteropolyesters of different molecular composition, microstructure, thermal and physical properties were detected in living microbes. Properties of PHA are fixed by the monomers building up the polyester, and by the polymer's microstructure, hence, if the PHA are blocky structured or if their monomers are randomly distributed. The types of monomers present in PHA are determined by the substrates provided to the cells, hence, the combination of main carbon source and co-substrates (precursors) of a structure chemically related to given monomers $(6,7)$. The molecular mass of PHA, which can range to some MDa, is strongly influenced by the type of carbon source, the production strain, and the activity of the enzyme PHA synthase, which polymerizes monomers to PHA polyester chains; PHA synthase activity, in turn, is determined by the process conditions ( $\mathrm{pH}$-value, temperature, etc.) and the current carbon source availability. To cope with the obvious complexity of PHA molecules occurring at the same time in a biological system in terms of monomer composition and degrees of polymerization, the expression "PHAome" was recently introduced as a relevant technical term in the PHA-related scientific literature (36). Fig. 2 illustrates the general chemical structure of PHA biopolyesters. 


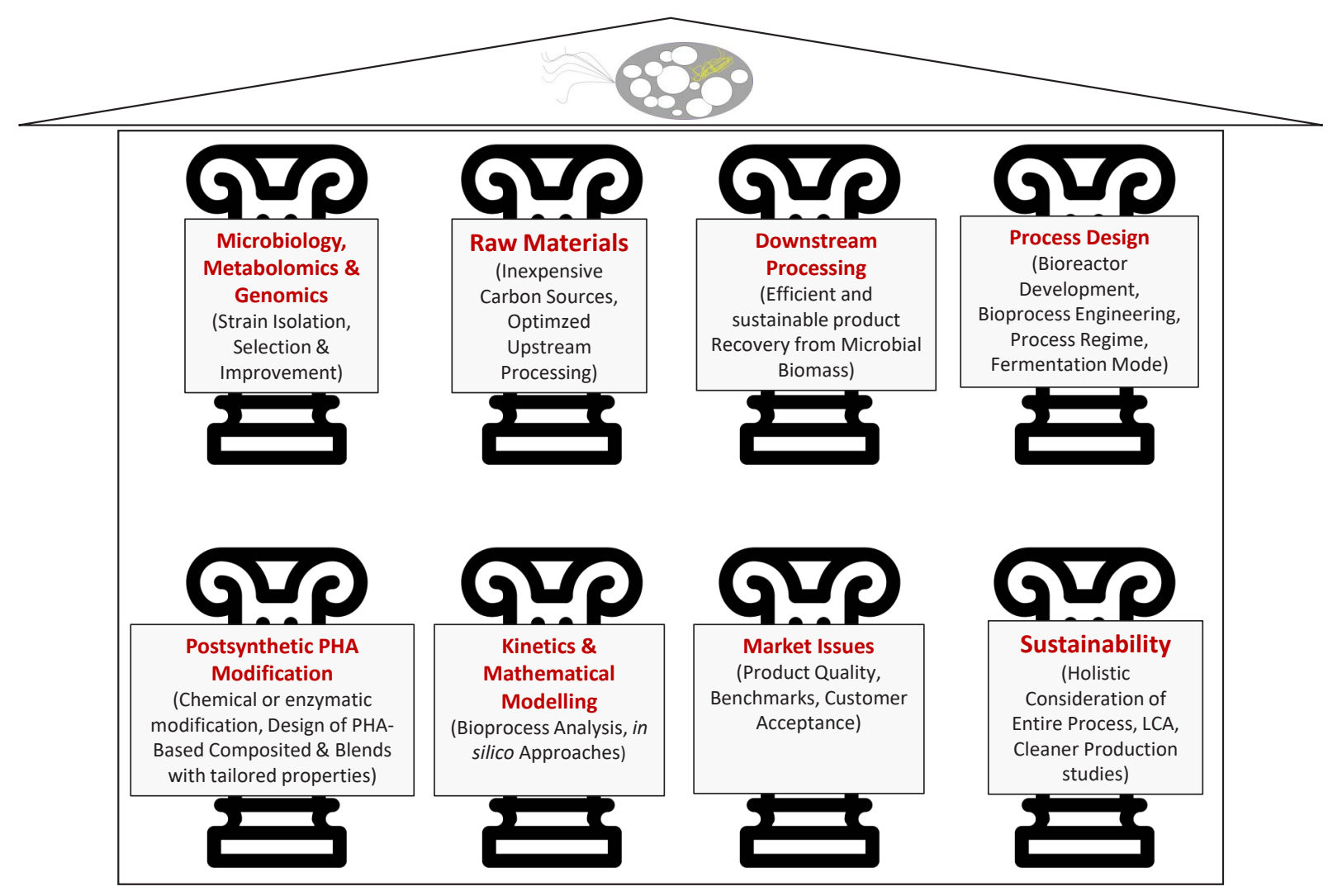

Figure 3. The eight pillars of cost-efficient and sustainable PHA manufacturing.

The improvement of large-scale productivity, cost efficien$c y$, and strain performance demands optimization procedures of different process steps. This includes the quest for new wild type and genetically modified microbes, development of a process design adapted to the kinetic characteristics PHA production, and ecologically benign and efficient techniques for separation of PHA and residual non-PHA biomass. Only the synopsis of these steps allows ecologically feasible and sustainable manufacturing of PHA $(6,37,38)$. Fig. 3 illustrates the eight pillars needed to produce PHA biopolyesters in a cost-efficient and sustainable fashion. The present review summarizes efforts of our research group and our consortium partners, and of other authorships focusing on the use of waste streams from the cheese making and the animal processing industry.

\section{Available raw materials for PHA biosynthesis}

Purified sugars, expensive fatty acids, or edible oils are traditionally used as substrates for PHA biosynthesis; therefore, about $50 \%$ of the total PHA production cost is allotted to the raw materials (substrates) (39). As a paradigm shift, inexpensive carbon-rich substrates are currently exploited to enable economically practical PHA production. Especially carbonaceous waste- and byproducts of agriculture, forestry, horticulture, and food industry have already been tested as substrates for PHA biosynthesis on different production scales. Here, it should be noted that the choice of feedstocks can impact PHA quality regarding the polymer composition on the level of monomers, the molecular mass (39-41), and can affect PHA's sensory quality in terms of odor or pigmentation (42).

Such inexpensive substrates are expected to meet various basic requirements:

- Availability of feedstock in sufficient quantity

- Constant feedstock quality throughout the whole year ("off-season disposal")

- Composition of individual feedstock batches fluctuating as little as possible

- Logistics for collection and transportation of feedstock easy to be accomplished

- Suitability for storage (stability and resistance against spoilage, e.g., by microbial action)

- No competition with food and feed application (use of " $2^{\text {nd }}$-generation feedstocks")

Regarding suitability for storage, easily perishable raw materials such as molasses can be converted via anaerobic fermentation towards storable intermediates like lactic acid or volatile fatty acids, which, in a second process stages, act as feedstocks for aerobic PHA production. This strategy was successfully demonstrated by using green grass juice, which was anaerobically fermented towards ensilage; pressed silage juice, rich in lactic acid, minerals, and nitrogen-containing compounds, turned out to be a feasible, stable feedstock to thrive the PHA producing organism Cupriavidus necator (43). Regarding collection and transportation of raw materials, it is reasonable to integrate PHA production facilities (bioreactor, downstream 
processing equipment) into such already running industrial production lines, where the feedstock is directly generated as a waste stream. For ethical reasons, any conflict with competing applications of the feedstock, especially use for human nutrition, has to be circumvented in order to secure food safety (6).

These restrictions clearly demonstrate that, although the idea of PHA production from inexpensive substrates is generally accepted by the scientific community, above listed obstacles need to be considered when planning a new PHA production process based on "2 ${ }^{\text {nd }}$-generation feedstocks" on industrial scale. Moreover, it was previously reported that applying inexpensive substrates reduces PHA productivity when compared to production setups using purified substrates. This is often due:

- Microbial production strain not adapted to feedstock

- Too low carbon source concentration in the feed stream

- Presence of substances inhibiting growth and PHA accumulation kinetics

Insufficient conversion of a new feedstock by microbial production strains can often be overcome by adaptation of organisms to the new substrate by consecutively thriving the strain in a series of pre-cultures containing this substrate. Metabolic bottle necks in substrate conversion can often be solved by tools of genetic engineering. Low carbon source concentration in the substrate feed solution makes the process less efficient, particularly in the case of fed-batch cultivation setups; here, the low concentrated feed solution dilutes the fermentation broth, thus increasing the volume. Low overall productivity in turn encumbers the aspired saving of production costs, because the bioconversion would take longer process time, and a higher total quantity of substrate to generate the same quantity of product. This causes higher operating and capex costs, particularly in large-scale production (44).

Therefore, upstream processing of feedstocks needs optimization to generate feed solutions rich in carbon source and low in inhibiting compounds. Such approaches were demonstrated for the feedstock whey. Because sweet whey contains only about 4-5 wt.- $\%$ of the main substrate lactose, an ultrafiltration step can be applied to separate the protein-rich fraction (whey retentate) from the lactose-rich fraction (whey permeate), which contains about 20-21 wt.-\% lactose. As shown by Ahn et al., feeding whey permeate instead of original whey substantially reduces the volume increase of the cultivation broth (45). Further substrate concentration can be achieved by subsequent hydrolysis of whey permeate (enzymatically or chemically); this generates equimolar glucose/galactose mixtures, which can be further concentrated by water evaporation up to the solubility limit of the of the two monosaccharides, thus generating a feed stream with about 50 wt.-\% carbon source (46). More technological advanced solutions for successfully using diluted substrate streams are so called cell recycling bioreactor systems; here, the fermentation broth passes through an external filtration membrane module coupled to the bioreactor to retain biomass, which flows back into the bioreactor, but the low-substrate supernatant gets discharged. In the case of using a whey powder solution as substrate for PHA production by recombinant Escherichia coli, this approach was successfully demonstrated by Ahn et al. (47) More recent studies report cell recycling for enhanced PHA production by C. necator DSM 545 on glucose, which resulted in high cell density and drastically increased volumetric productivity for PHA (48).

For removal of inhibiting by-products generated by hydrolysis of inexpensive raw materials such as lignocelluloses like furfural, 5-hydroxymethyl furfural, and others, a simple solution can be to remove such compounds by separation with charcoal or lignite. This approach was only recently performed by Kucera et al., who removed inhibiting compounds from the hydrolysate of spruce dust, making this hydrolysate a suitable substrate mix for PHA biosynthesis by two different Burkholderia sp. (49). A similar technique was used by Silva et al., who converted rather toxic bagasse hydrolysate into a substrate for PHA production by Burkholderia sp. by using simple charcoal treatment (50). Importantly, all Burkholderia sp. used by these two groups of researchers were able to convert both hexose (glucose) and pentose (xylose) generated by hydrolysis of the lignocellulose (spruce dust and bagasse) towards PHA, which increases the overall substrate-to-product yield. In the case of bagasse hydrolysate, PHA fractions in biomass and substrate conversion yields were even higher than observed when using purified xylose. A similar charcoal pre-treatment was used by Haas et al. for detoxification of chicory root hydrolysate, which, after this step, was successfully used as " $2^{\text {nd }}$-generation feedstock" for PHA production by C. necator (51).

As major by-product of biodiesel production via alkaline methanolysis of lipids, crude glycerol phase (CGP) is generated at increasing global quantities; CGP contains about 65 wt.-\% of the substrate glycerol plus various additional components such as water, biodiesel residues, free fatty acids, acylglycerides, soaps, and minerals. To be used as fermentation substrate, CGP requires demethanolization to remove this methanol, which is strongly inhibiting for many microbes. $(52,53)$. Methanol removal can be managed by vacuum-assisted evaporation, or thermally using so called "preheat tanks" (53-55). Moreover, the glycerol content in CGP can be increased by removing water via distillation, vacuum dehydration, or more advanced phase separation procedures. In addition, some bacterial specialists are able to accept both methanol and glycerol as carbon sources, as successfully demonstrated by Braunegg et al., who applied Methylomonas extorquens and non-purified CGP for PHA production. In a diauxic way, this bacterial species first converts methanol before using glycerol (40). On the basis of a mixed microbial culture supplied with CGP as sole carbon source in a sequencing batch reactor, Moita et al. demonstrated parallel consumption of glycerol and methanol. The mixed culture reached up to 47 wt.- $\%$ PHA in biomass, and a promising PHA productivity of $0.27 \mathrm{~g} /(\mathrm{L} \cdot \mathrm{d})(56)$.

Direct conversion of strongly inhibiting substrates by metabolically versatile organisms was reported by Ward et al. These authors used the strain Pseudomonas putida CA-3 for growth 
and PHA accumulation on pyrolyzed poly(styrene) (PS) as carbon source. Hence, the value-added conversion of a spent petrochemical plastic was combined with biosynthesis of a "bioplastic". PS pyrolysis generates a gaseous mixture of styrene and other aromatic compounds. The gaseous substrate feed was added into the bioreactor together with the aeration stream. Rather modest volumetric PHA productivity of $0.03 \mathrm{~g} /(\mathrm{L} \cdot \mathrm{h})$, but high intracellular fraction in biomass of about $0.57 \mathrm{~g} / \mathrm{g}$ were reported (57). A more recent report for using follow-up products of spent petrochemical plastics for PHA biosynthesis was provided by Johnston and colleagues; these authors pyrolyzed waste polyethylene (PE) to generate non-oxygenated $\mathrm{PE}$ wax (N-PEW), the latter being used as co-substrate in cultivations of $C$. necator H16. N-PEW is easy to manufacture and has hardly any industrial use, hence, it constitutes more or less a waste material. Polyester characterization revealed that the PHA based on N-PEW was a copolyester costing of the two monomers 3-hydroxybutyrate (HB) 3-hydroxyvalerate (3HV) (58).

\section{WHEYPOL - Using a side stream of cheese making industry for PHA production}

During cheese and casein production processes, whey is generated at huge quantities as the aqueous side stream of the acidic or enzymatic coagulation of milk casein ("transformation"). Whey represents up to $95 \%$ of the entire volume of processed milk (59), with about $9 \mathrm{~L}$ of whey being generated per $\mathrm{kg}$ of produced cheese (60). Reliable data of OECD and FAO for 2008 estimate a global whey production of about $1.60^{*} 10^{8} \mathrm{t}$ per year, with an annual increase by 1-2\% (59).

Whey accrues as a surplus stream in different global areas (61), mainly in Europe and North America; in 2008, about 5 $\mathrm{x} 10^{7} \mathrm{t}$ of whey were produced in the EU only. Because of cow milk being the worldwide leading raw material for cheese production, bovine whey embodies the major fraction of the global whey quantity (62). In addition to countries of the Northern world hemisphere, increasing volumes of whey are currently also generated in southern countries; for example, 270,000 tons annually are generated in India, constituting a real waste stream there without any further use (63).

As a matter of fact, whey has some market applications, such as for production of dietary supplements for body builders, sweets, whey-based drinks, technological additives for processing meat or producing ice cream, chocolate substitute, or baby food; moreover, also the cosmetic and the pharmaceutical sector has a certain demand for whey (63). Although whey, because of its high content in proteins, sugars, lipids, vitamins, and minerals like calcium has a considerable nourishing value with $100 \mathrm{~g}$ of whey corresponding to more than $100 \mathrm{~kJ}$ of nutritional energy, its application in the food sector is restricted by about $75 \%$ of all adults worldwide suffering from lactose intolerance (hypolactasia) caused by insufficient activity of the enzyme $\beta$-galactosidase (lactase). Particularly, hypolactasia is frequently diagnosed in South European regions and countries of the Southern world hemisphere (64). Together with the cur- rent price drop for whey powder, this makes clear that alternative policies for whey valorization are needed. In parallel, we witness a current controversy on the excessive volume of milk, which is currently flooding the European market. Upgrading whey to an innovative raw material would open the door to support milk-producing companies, and offer stay-options for agrarians in underprivileged regions, which, in turn, could generate socio-economic benefit.

Traditional treatment of whey encompasses dumping into aquatic environments, disposal in caves, dispersion over fields, or application as livestock feed. However, whey's lion's share these days is disposed as waste, resulting in tremendous ecological contamination due to its high biochemical and chemical oxygen demand of more than 40,000 ppm and 50,000 ppm, respectively. Due to depletion of dissolved oxygen, whey disposal into the sea causes deterioration of aerobic marine microbes and animals (65). Lactose, whey's major carbon compound, and the protein fraction are mainly responsible for the high environmental burden caused by whey. Releasing whey on fields to manure them severely affects the physical and chemical structure of soil, which negatively affects crop yields (66). Currently generated quantities of whey by far surmount those to be used as livestock fodder for ruminants and pigs. In Italy, feeding pigs with whey for production of ham of protected regional label ("Denominazione Origine Protetta") is already barred (46). One liter of milk transformed for cheese or casein production yields one liter of whey to be treated accordingly, with each liter of whey containing about 40-50 g of lactose. Alone in the North Italian Po-region, where numerous large dairies are located, about 1,000 t of surplus whey, corresponding to about 50 tons lactose, are generated day by day $(46,67)$ ! Hence, there is an urgent need for new, sustainable, safe, and valorizing strategies to manage surplus whey; using it as feedstock for biotechnological PHA production is among the most auspicious options. Fig. 4 shows the process steps from whey to PHA biopolyesters.

During the project WHEYPOL, financed by the $5^{\text {th }}$ Framework programme of the EU, different gram-negative microbial species were tested for production of PHA biopolyesters of different monomeric composition, using either hydrolyzed or non-hydrolyzed whey permeate as carbon source (68). Here, the studied eubacterial production strains Hydrogenophaga pseudoflava and Burkholderia parafunghorum revealed rather modest performance in terms of kinetics and productivity (6870). In contrast, the haloarcheal strain Haloferax mediterranei displayed fast biomass growth, high PHA productivity, and high stability during long-term cultivation setups. As another remarkable property, this organism synthetizes PHA copolyesters consisting of $3 \mathrm{HB}$ and $3 \mathrm{HV}$ (PHBHV) from hydrolyzed whey permeate without the need for $3 \mathrm{HV}$-related co-substrates $(68,70)$; PHA producers studied before convert sugars as present in hydrolyzed whey permeate to poly(3-hydroxybutyrate) (PHB) homopolyester, which is of minor material quality than PHBHV copolyesters. This phenomenon was only recently clarified by Han and colleagues, who revealed that $H f x$. med- 


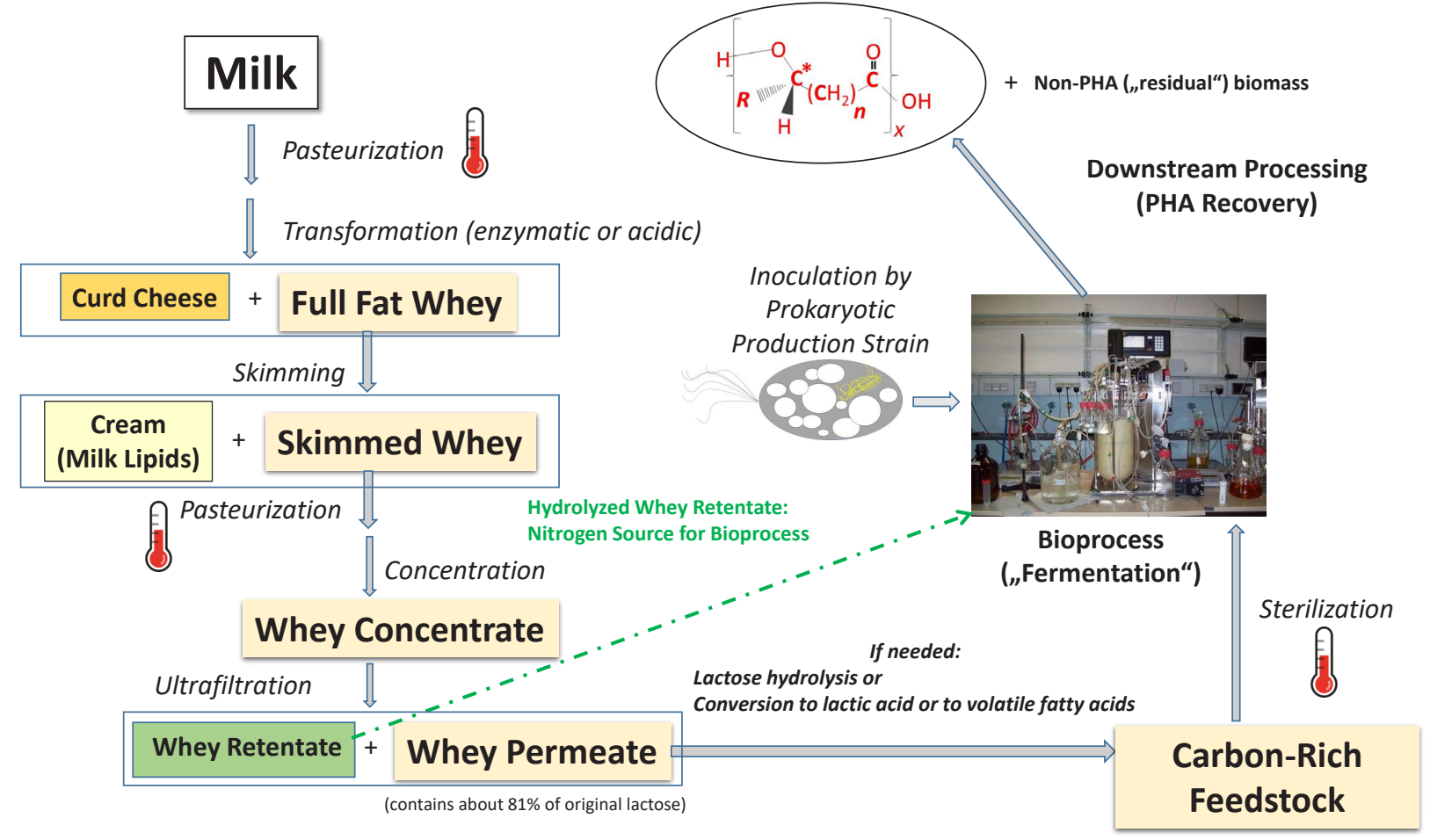

Figure 4. Process steps for PHA production starting from surplus whey as raw material.

iterranei resorts to a range of active propionyl CoA-supplying pathways, which generate the $3 \mathrm{HV}$ precursor propionyl-CoA (71). Using hydrolyzed whey permeate, this organism was cultivated on pilot scale in a $200 \mathrm{~L}$ bioreactor to get valid data for an economic process assessment; production costs for one $\mathrm{kg}$ of PHBHV produced by this strain from hydrolyzed whey permeate were estimated with less than $3 €$ per $\mathrm{kg}$. This auspicious value was possible by the fact that, due to the high salinity of the cultivation medium of about $200 \mathrm{~g} / \mathrm{L} \mathrm{NaCl}$, cultivation of $H f x$. mediterranei can be accomplished even in an unsterile process. Moreover, the in-house availability of the feedstock (whey), considered a waste stream, was not cost-generating. Moreover, PHA granules can be released from biomass via a convenient, solvent-free recovery method: PHA-rich cells burst immediately when being exposed to hypotonic medium (distilled water), setting free PHA-granules, which can easily be harvested by centrifugation (17). Moreover, it was more recently demonstrated that considerable shares of spent fermentation broth and saline cell debris (remaining after cell disrupture) can be recycled, hence, used as nutrients in subsequent fermentation setups (72); this recyclability not only safes costs, but in parallel, drastically reduces the environmental burden connected to disposal of these highly saline waste streams. Recently, follow-up studies accomplished by Pais and colleagues paved the way to optimize galactose conversion by Hfx. mediterranei, a bottle neck during the WHEYPOL research due to the significantly faster uptake of glucose in comparison to galactose, causing an enrichment of the latter in the fermentation broth. After careful optimization of the composition of the fermentation medium, these authors demonstrated that fine-tuning the concentration of trace elements in the medium is essential to boost the galactose catabolism, thus enabling the conversion of the entire carbon source (73). To date, Hfx. mediterranei is considered the most auspicious wild-type strain for PHA production on whey as substrate. Subsequent studies using this strain focused on the application of other inexpensive substrates for PHBHV biosynthesis by this organism. In this context, CGP turned out as feasible substrate; combined with co-feeding of precursors for 4-hydroxybutyrate ( $4 \mathrm{HB}$ ) biosynthesis, $\mathrm{PHBHV}$ copolyesters and poly(3HB-co-3HV-co-4HB) (PHBHV4HB) terpolyesters of tailored composition were obtained by Hermann-Kraus and colleagues (74). Other research groups used extruded rice bran (75), extruded starch (76), or waste streams from the olive oil manufacturing (77) as inexpensive substrates for Hfx. mediterranei-mediated PHBHV production. For the whey-based process, a Life Cycle Assessment study (LCA) was carried out by the WHEYPOL project team to evaluate ecological sustainability of this process. As the main conclusion, the calculated ecological footprint was comparable to competing petrol-based plastics like PE, and underlined the importance of above mentioned recycling of spent fermentation broth and saline cell debris. In addition, the LCA study compared the new PHA production process with the production of whey powder as an established application of surplus whey; according to the LCA results, the novel PHA production process outperforms the production of whey powder in environmental terms (17).

In contrast to Gram-negative microbes, the use of Gram-positive organisms for whey-based PHA biosynthesis is only scarcely described in literature. However, Obruca and colleagues used Bacillus megaterium CCM 2037 for direct 
conversion of not hydrolyzed cheese whey towards PHB homopolyester. After optimization of the composition of the nutrient broth by growth supplements, these authors succeeded in drastically improving PHB production to more than $1 \mathrm{~g} / \mathrm{L}$ in nitrogen-deprived cultures, which is about the 50 -fold concentration than achieved using not supplemented, native whey. Furthermore, addition of $1 \%$ ethanol as additional stress factor at the onset of the stationary growth phase improved PHB concentration by about $40 \%$ to about $1.5 \mathrm{~g} / \mathrm{L}$ PHB (78).

Because many promising PHA producing microbes are not able to convert lactose directly due to lacking or deficient $\beta$-galactosidase activity, viable hydrolysis techniques are required to split the disaccharide lactose into the monosaccharides glucose and galactose. In analogy to lignocelluloses hydrolysis under harsh conditions, whey permeate hydrolysis using strong acids (typically $\mathrm{HCl}$ or $\mathrm{H}_{2} \mathrm{SO}_{4}$ ) at high temperature and pressure generates a brown liquid rich in various inhibiting compounds, which requests further purification. Enzymatic hydrolysis displays a convenient alternative to the use of acids; only one enzyme ( $\beta$-galactosidase), which operates at mild conditions of temperature and $\mathrm{pH}$-value, is needed to completely convert lactose into the monosaccharides; this is different to the multi-enzyme cocktail requested to hydrolyze lignocellulose materials into a sugar solution. In the WHEYPOL project, inexpensive and customer-friendly $\beta$-galactosidase formulations (Maxilact ${ }^{\mathrm{TM}}$, company DSMZ), which are used in food technology for lactose hydrolysis, were successfully applied to prepare the substrate for PHA production (79).

Alcalase was used by Obruca and colleagues to hydrolyze whole whey (WWH). WWH was used as a complex nitrogenand carbon source to increase cell growth and $\mathrm{PHB}$ production by $C$. necator H16, with PHB yields being considerably higher than in control cultivations run without supplementation of WWH. Under controlled cultivation conditions in a laboratory bioreactor, C. necator cultivated on waste cooking oil (WCO) as main carbon source plus WWH produced 28.1 $\mathrm{g} / \mathrm{L} \mathrm{PHB}$, and achieved an excellent WCO-to-PHB yield of $0.94 \mathrm{~g} / \mathrm{g}(80)$.

Whey proteins were also used to coat poly(ethylene) (PE) or poly(ethylene terephthalate) (PET) plastic films; this way, bio-based, recyclable, and biocompatible materials with high oxygen and water vapor barrier were designed, which could potentially be used for food packaging; especially the low oxygen permeability and moisture transfer attracts attention for these new materials for extension of packaged food shelf life (reviewed by (81)). When using a commercial compostable carrier film (Bio-FlexR F $2110^{\mathrm{TM}}$ ) instead of PE or PET for coating with whey protein, resulting composites are readily biodegraded and composted without negatively impacting compost quality (82). Further developments in this direction should aim at the substitution of PE or PET by other bioplastic films, most preferably made of PHA produced from whey-permeate.

\section{ANIMPOL - Using waste streams of animal processing for biotechnological polyester production}

An estimated annual quantity of $5 \times 10^{5}$ tons of lipid-rich waste is generated by the European animal processing industry, which includes slaughterhouses, rendering companies, or meat-converters (83). The project ANIMPOL, financed by the $7^{\text {th }}$ Framework Program of the EU, consisted of a consortium of seven academic and four industrial partners (84). Based on the experiments carried out in the context of the ANIMPOL project, it could be demonstrated that lipids can expediently be extracted from these waste materials, and undergo transesterification to generate fatty acid methyl esters (FAME), which can be used as biodiesel, a renewable biofuel. In addition to the huge quantities of animal-based waste, the "mad-cow-disease" (BSE) crisis some years ago, which provoked the question of innovative, value-adding and sustainable conversion of meat and bone meal (MBM), gave also reason to realize this project (85). Hence, the project consortium searched for value-adding alternatives to the contemporary incineration of animal-based waste. From a holistic point of view, the results should support the food industry sector, and moreover, also contribute to food security.

Looking at the fatty acid pattern of animal-based lipids, we notice a large share of saturated fatty acids, mainly pelargonic (C9:0), pentadecylic (C15:0), palmitic (C16:0), margaric (C17:0), or stearic acid (C18:0); after transesterification of such lipids, these saturated fatty acids also occur in animal-based FAME (86). However, a high share of saturated fatty acid esters (SFAE) in biodiesel causes increase of the cold filter plugging point; this impedes its use as engine fuel at low temperature by precipitation of solid SFAE particles. Alternatively, the SFAE and unsaturated FAME fraction can be separated by simply precipitating SFAE via cooling; by a subsequent filtration step, SFAE can be easily recovered, and finally converted biotechnologically to PHA biopolyesters by various powerful microbial species. Taking into account a theoretical conversion yield of 0.7 g PHA per g SFAE (based on the experimental data from ANIMPOL) and the available amounts of animal-based waste lipids, 35,000 annual tons of PHA could theoretically be produced (83). The unsaturated FAME fraction remaining after separation of SFAE can be used as valuable " $2^{\text {nd }}$-generation biofuel".

This transesterification process generates about $0.1 \mathrm{~kg}$ CGP as main side product per $\mathrm{kg}$ lipids (triacylglycerides) (87). Calculating with the entire biodiesel quantity produced these days in the $\mathrm{EU}\left(2-3 \times 10^{7}\right.$ tons per year), more than $2 \times 10^{6}$ tons of CGP are generated as by-product, which is considerably exceeding the quantities of glycerol needed for its current uses in the food or cosmetic sector (83). As mentioned before, various microbial species grow well on glycerol as sole carbon source, and, under challenging conditions, transform this triol into PHA (88). If used to generate microbial biomass, more than $0.4 \mathrm{~g}$ biomass or PHA can theoretically be produced per gram of metabolized glycerol (89). Regarding the amounts of 


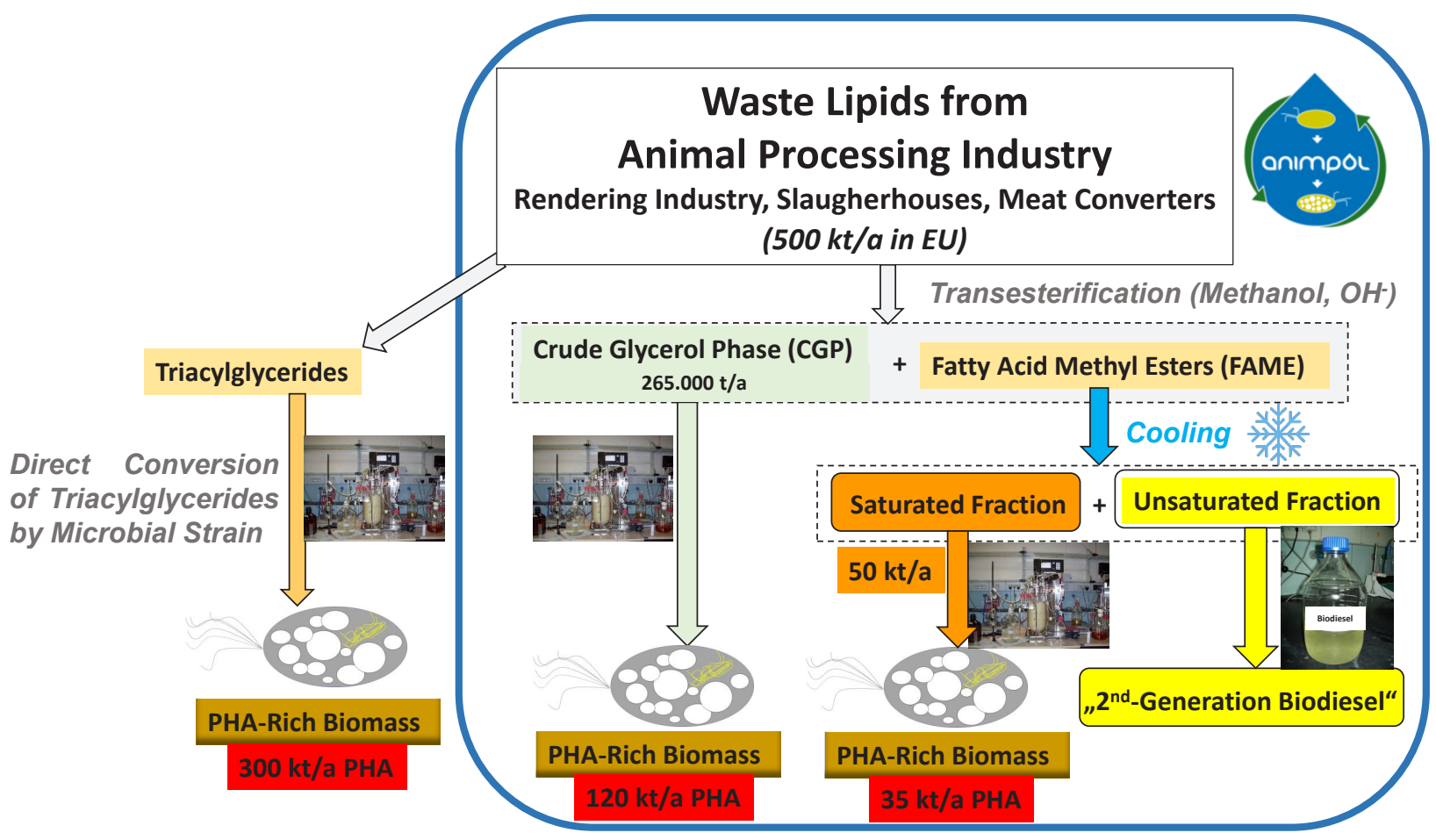

Figure 5. Theoretically accessible quantities of PHA starting from lipid waste of the European animal-processing industry.

waste lipids generated by the European animal processing industry, more than 20,000 tons of PHA-containing biomass are accessible per year only from the accruing CGP (90-92). Fig. 5 illustrates the quantities of lipid-rich waste fractions stemming from the rendering and animal processing industry currently accruing in the EU, and the amounts of PHA biopolyesters theoretically accessible thereof.

Already two decades ago, Cromwick et al. studied PHA production on animal-based waste lipids using the Gram-negative bacteria Pseudomonas oleovorans, Pseudomonas resinovorans, Pseudomonas putida, and Pseudomonas citronellolis. Free fatty acids (FFA) from tallow and tallow triglycerides were used as carbon sources for biomass formation and PHA accumulation. Using FFA, significant microbial growth and PHA biosynthesis were reported for these strains. Mass fractions of PHA in biomass differed from $0.03 \mathrm{~g} / \mathrm{g}$ (P. citronellolis), $0.15 \mathrm{~g} / \mathrm{g}$ ( $P$. resinovorans), $0.18 \mathrm{~g} / \mathrm{g}$ (P. oleovorans), and $0.19 \mathrm{~g} / \mathrm{g}$ (P. puti$d a$ ). Non-hydrolyzed tallow was used for bacterial growth and PHA production only by $P$. resinovorans; also for this substrate, $0.15 \mathrm{~g}$ PHA per g CDM were achieved when using this strain. With $12.8 \mathrm{U} /(\mu \mathrm{L} \cdot \mathrm{min})$, P. resinovorans exhibited the highest lipase activity among these four bacterial species; for all other strains, lipase activity was less than $0.03 \mathrm{U} /(\mu \mathrm{L} \cdot \mathrm{min})$. Regarding the monomer composition of the PHA accumulated by the individual strains from these animal-based carbon sources, the identified building blocks ranged from C4 (3HB) to C14 (3-hydroxytetradecanoate [3HT]); C8 (3-hydroxyoctanoate, 3HO) and $\mathrm{C} 10$ (3-hydroxydecanoate, $3 \mathrm{HD}$ ) were the predominant monomers; even mono-unsaturated side chains was detected in some longer monomers (C12 and C14), in which biosyn- thesis of unsaturated monomers originating from presence of a certain amount of unsaturated fatty acids in tallow (93).

Follow-up experiments with $P$. resinovorans compared the effect of triacylglycerides originating either from animals or plants. Again, it was shown that the use of animal-based lipids and most of the plant-derived oils resulted in PHA harboring $\mathrm{C} 4$ to $\mathrm{C} 14$ monomers, with $3 \mathrm{HO}$ and $3 \mathrm{HD}$ monomers as the predominant building blocks. Because triacylglycerides from plants have higher amounts of unsaturated fatty acids than lipids originating from animals, plant oil-derived PHA revealed higher degrees of unsaturation, which drastically impacts the thermoanalytical biopolyester properties in terms of decreased melting temperature $\left(T_{m}\right)$, glass transition temperature $\left(T_{q}\right)$, and melt fusion enthalpy $\left(\delta \mathrm{H}_{m}\right)$. Molecular mass of the individual PHA samples showed rather constant number-average molar mass $\left(M_{n}\right)$ values between 65 and $101 \mathrm{k} \mathrm{Da}$, and polydispersity indices $\left(P_{i}\right)$ between 1.6 and $1.8(94)$.

During the ANIMPOL project, animal-based SFAE was used as substrate instead of tallow for bioreactor cultivation of C. necator under controlled temperature, $\mathrm{pH}$-value and aeration. During the first cultivation phase, a nutritionally balanced medium containing ammonium ions as nitrogen source and SFAE as carbon source was used. When the concentration of PHA-free biomass reached $7 \mathrm{~g} / \mathrm{L}$ after $23 \mathrm{~h}$ of cultivation, supply of nitrogen source was stopped, and the intracellular carbon flux was redirected from biomass growth to predominant PHA biosynthesis. About $28.0 \mathrm{~g} / \mathrm{L}$ PHA and a PHA fraction in biomass of $0.80 \mathrm{~g} / \mathrm{g}$ were obtained in this process. During the microbial growth phase (presence of nitrogen source), $C$. necator grew at a specific growth rate $\mu_{\max }$ of $0.171 / \mathrm{h}$, which 
is comparable to cultivations of this organism on traditional substrates like glucose (83). Remarkably, the yield for biomass production from SFAE reached $0.6 \mathrm{~g}$ biomass per $\mathrm{g}$ SFAE, which is significantly higher than reported for traditional PHA substrates like sugars or glycerol, where the metabolic pathways (2-keto-3-desoxy-6-phosphogluconate pathway and/ or glycolytic substrate catabolism to pyruvate, and oxidative decarboxylation of pyruvate to acetyl-CoA) do not allow conversion yields higher than $0.48 \mathrm{~g} / \mathrm{g}$. In contrast, fatty acids are converted by the $\beta$-oxidation pathway, which generates a number of acetyl-CoA units analogous to the fatty acid's carbon chain length; here, no carbon loss by oxidative decarboxylation takes place. Acetyl-CoA in turn serves as building block for biomass and PHA. Volumetric PHA productivity of this process was $0.94 \mathrm{~g} /(\mathrm{L} \cdot \mathrm{h})$, which is already competitive with well-established PHA production processes based on substrates of nutritional value. E.g., the semi-industrial PHA production process from cane sugar at PHB INDUSTRIAL S.A. in Brazil has a volumetric PHA productivity of $1.44 \mathrm{~g} /(\mathrm{L} \cdot \mathrm{h})$ (95). Analysis of the product's monomer composition showed that the PHA was a copolyester mainly consisting of $3 \mathrm{HB}$ monomers plus a minor fraction ( $0.84 \mathrm{~mol}-\%)$ of $3 \mathrm{HV}$, probably stemming from SFAE-fatty acids with an odd number of carbon atoms: at the end of $\beta$-oxidation of odd-numbered fatty acids, one propionyl-CoA molecule remains in addition to the acetyl-CoA molecules split off one after the other. Condensation of propionyl-CoA and acetyl-CoA generates 3-hydroxyvaleryl-CoA, which finally acts as $3 \mathrm{HV}$-precursor. Thermoanalysis results for this product showed typical values for scl-PHA with $T_{m}=$ $169.0^{\circ} \mathrm{C}, T_{g}=4.6^{\circ} \mathrm{C}, M_{n}=204 \mathrm{kDa}$, and $P_{i}=1.50$; however, the material has a lower degree of crystallinity $\left(X_{c}=30.8 \%\right)$ than typically observed for PHB (83).

Follow-up experiments aimed at achieving a higher fraction of $3 \mathrm{HV}$ monomers in the copolyester by increasing the amount of those compounds in the substrate, which have an odd number of carbon atoms; higher $3 \mathrm{HV}$ fractions were aspired in order to decrease the copolyesters brittleness, $X_{c}$ and $T_{m}$, which facilitates its processibility. Therefore, SFAE obtained by transesterification of animal-based waste lipids was reduced to the corresponding alcohol analogues by sodium. Subsequently, these fatty alcohols were converted to the corresponding alkenes by the catalytic action of aluminum oxide; these alkenes were finally subjected towards oxidative ozonolysis, generating a mixture rich in numbered (C9-C17) carboxylic acids, which was used as substrate for cultivation of C. necator. Using this mixture as substrate, the molar $3 \mathrm{HV}$ fraction in PHA exceeded $0.06 \mathrm{~mol} / \mathrm{mol}$, with the isolated copolyesters displaying low $T_{m}\left(159^{\circ} \mathrm{C}\right)$, low $X_{c}(22.5 \%)$, and low $P_{i}(1.6)$, which makes them promising candidates for further processing to vendible biopolymer items (96).

This above described SFAE-based process was repeated by replacing SFAE by glycerol as sole carbon source. Also here, a controlled aerobic fed-batch bioreactor process with C. necator was carried out, with the nitrogen supply being stopped after $23 \mathrm{~h}$ in order to switch from the phase of biomass growth to predominant PHA biosynthesis. Maximum specific growth rate $\mu_{\text {max. }}$ and maximum specific PHA productivity $q_{P}$ reached $0.11 \mathrm{l} / \mathrm{h}$ and $0.16 \mathrm{~g} /(\mathrm{g} \cdot \mathrm{h})$, respectively. After $30 \mathrm{~h}, 0.65 \mathrm{~g}$ PHA per g CDM and a volumetric productivity for PHA of $0.98 \mathrm{~g} /$ (L.h) were obtained. The conversion yield for glycerol to biomass was considerably lower $(0.29 \mathrm{~g} / \mathrm{g})$ than observed for the same strain on SFAE as substrate. On glycerol, pure homopolyester $\mathrm{PHB}$ was generated without any traces of $3 \mathrm{HV}$ monomers. Thermoanalytical characterization of $\mathrm{PHB}$ delivered data typical for PHB with $T_{m}=173.0^{\circ} \mathrm{C}, T_{g}=5.6{ }^{\circ} \mathrm{C}, X_{c}=71.2 \%, M_{n}$ $=296 \mathrm{kDa}$, and $P_{i}=1.28(83)$.

Low structured mathematical models were developed by ANIMPOL consortium members for the two discussed PHA production processes by $C$. necator using SFAE or glycerol, respectively. These models were created to better understand the key points how to further optimize these processes regarding carbon and nitrogen source feeding. Developed models correlated well with the experimental results, hence, they were of high predictive power. The models revealed that, when using SFAE as carbon source, the bacterial culture needs to be well adapted to this substrate by thriving the strain in a series of pre-cultures containing this substrate. In addition, it was elucidated that consumption of the individual SFAEs (C14-C20 methyl esters) is directly proportional to their mass fraction, indicating that bacteria utilize them in a competitive way. Finally, based on the established models, $10-12 \mathrm{~g} / \mathrm{L}$ was suggested as the optimal SFAE concentration, which should be available constantly during the fermentation process, which determined the required substrate feeding rate (89).

In analogy to the experiments presented by Cromwick et al., P. citronellolis and Pseudomonas chlororaphis were studied in the ANIMPOL project on animal waste-based FAME as feedstock for biosynthesis of medium chain length PHA (mcl-PHA) $(97,98)$. For the organism $P$. citronellolis, $\mu_{\max }$ was determined with 0.10 and $0.08 \mathrm{l} / \mathrm{h}$, volumetric mcl-PHA productivity amounted to $0.036 \mathrm{~g} /(\mathrm{L} \mathrm{h})$ and $0.050 \mathrm{~g} /(\mathrm{L} \mathrm{h})$, and $m c l$-PHA fractions in biomass reached 0.20 and $0.27 \mathrm{~g} / \mathrm{g}$, when comparing two parallel bioreactor cultivations. The produced mcl-PHA mainly consisted of $3 \mathrm{HO}$ and $3 \mathrm{HD}$ building blocks in addition to minor amounts of the monomers 3HDD, 3-hydroxynonanoate $(3 \mathrm{HN}), 3$-hydroxyhexanoate $(3 \mathrm{HHx})$, and 3-hydroxyheptanoate (3HHp). Using NMR, the presence of traces of unsaturated and, surprisingly, $3 \mathrm{HV}$ monomers in these polyesters was also confirmed. Thermoanalysis measurement reported values typical for $m c l$-PHA, with $T_{m}$ of $48.6^{\circ} \mathrm{C}$ and $53.6^{\circ} \mathrm{C}, T_{g}$ of $-46.9^{\circ} \mathrm{C}$ and $-43.5^{\circ} \mathrm{C}, X_{c}$ of $12.3 \%$ and $10.4 \%, M_{n}$ of 35,000 and 196,000, and $P_{i}$ values of 1.9 and 2.5 for the two parallel cultivation experiments (97).

Repeating this process with the production strain $P$. chlororaphis resulted in a $\mu_{\max }$ of $0.131 / \mathrm{h}$, a volumetric productivity of $0.14 \mathrm{~g} /(\mathrm{L} \mathrm{h})$, and a PHA fraction in biomass of $0.23 \mathrm{~g} / \mathrm{g}$. Analogous to the previous cultivations with C. necator and $P$. citronellolis, the SFAE conversion yield towards biomass was remarkably high $(0.62 \mathrm{~g} / \mathrm{g})$. The generated $\mathrm{mcl}$-PHA mainly consisted of $3 \mathrm{HO}$ and $3 \mathrm{HD}$ building blocks and lower fractions 
of $3 \mathrm{HDD}, 3 \mathrm{HN}, 3 \mathrm{HHx}$, and $3 \mathrm{HHp}$. This biopolyester exhibited characteristics of a highly amorphous resin without crystalline moieties, which was evidenced by $T_{m}$ and $X_{c}$ not being exactly determinable. Similar to the biopolyesters obtained by $P$. citronellolis, $T_{g}$ was very low $\left(-47.0^{\circ} \mathrm{C}\right)$. Slightly higher molecular mass values $\left(M_{n}=38 \mathrm{kDa}, P_{i}=1.93\right)$ were obtained for the $P$. chlororaphis biopolyesters than reported for the product of $P$. citronellolis (98).

After the end of the ANIMPOL project, Riedel and colleagues applied native industrially rendered waste animal lipids without prior conversion to FAME. C. necator DSM 428 and its mutant strain C. necator Re2058/pCB113, which harbored $\mathrm{scl} / \mathrm{mcl}$-PHA-synthase genes of Rhodococcus aetherivorans to enable biosynthesis of the copolyester $\mathrm{P}(3 \mathrm{HB}-\mathrm{co}-3 \mathrm{HHx})$, were used for the experiments. Animal waste fractions of avian, bovine, porcine, and game origin were used to recover the lipids via high-pressure thermolysis. Analysis of the isolated lipids showed that C16:0, C18:0, C18:1 and C18:2 were the predominant fatty acids. These lipids were compared to using tallow and WCO as substrate for cultivation of the bacteria. When cultivated on the different lipids, C. necator DSM 428 (wild type) synthesized $\mathrm{PHB}$ homopolyester at high mass fraction (0.79-0.82 g PHB per g CDM). On tallow as sole carbon substrate, the authors obtained a PHB concentration of $24 \mathrm{~g} / \mathrm{L}$, and a volumetric productivity for PHB of $0.3 \mathrm{~g} /(\mathrm{L} \cdot \mathrm{h})$. Dependent on the applied waste stream, 0.49-0.72 g PHA per g CDM were obtained when using the recombinant organism; the molar $3 \mathrm{HHx}$ fraction in the copolyester $\mathrm{P}(3 \mathrm{HB}-$ co-3HHx) amounted to $0.16-0.27 \mathrm{~mol} / \mathrm{mol}$. The recombinant strain was later cultivated under controlled conditions in a laboratory bioreactor using low-quality animal waste lipids; here, a CDM of $45 \mathrm{~g} / \mathrm{L}$ containing $0.6 \mathrm{~g} / \mathrm{g} \mathrm{P}(3 \mathrm{HB}-$ co- $3 \mathrm{HHx})$, a volumetric productivity for the copolyester of $0.4 \mathrm{~g} /(\mathrm{L} \cdot \mathrm{h})$, and a final $3 \mathrm{HHx}$ fraction in the polyester of $0.19 \mathrm{~mol} / \mathrm{mol}$ were obtained (99). Calculating with a conversion yield of 0.6 to $0.7 \mathrm{~g}$ PHA per g lipid (triacylglycerides), a theoretical quantity of about $3 \times 10^{5} \mathrm{t}$ PHA could be produced per year using the $5 \times 10^{5} \mathrm{t}$ of animal-based waste-lipids available in the EU (see Fig. 5).

Based on the ANIMPOL results from the experiments described above, Kettl et al. published a preliminary process design for PHA production based on slaughterhouse waste, encompassing transesterification of waste lipids and use of the SFAE fraction as carbon source. In this process scheme, the conversion of slaughtering waste from poultry, cattle, and pigs was considered, moreover, hydrolysis of waste materials prior to extraction to obtain higher lipid yields was taken into account. The authors also propose the utilization of hydrolyzed $\mathrm{MBM}$ as an inexpensive nitrogen substrate (100). This strategy of using MBM for thriving PHA-producing microbes was successfully demonstrated before for PHA production by $H f x$. mediterranei (39). Later, Titz et al. carried out further optimization of the ANIMPOL process design regarding the material- and energy streams and system boundaries (91). Special emphasize was dedicated to optimized acidic hydrolysis of the waste materials. For the first time, the use of hydrolyzed innards as nitrogen source for microbial growth was proposed. By applying Cleaner Production principles proposed by Schnitzer and Ulgiati (101), the process design was optimized towards minimizing generation of waste stream and energy loss. Moreover, the authors carried out a LCA study for environmental process evaluation (91).

Shahzad and colleagues accomplished a more detailed environmental assessment of PHA manufacturing starting from slaughterhouse waste as raw material, again based on elaborated ANIMPOL data. These authors compared, among other aspects, the influence of using diverse energy sources, which, in turn depends on the usual energy mix applied in different regions; this was used to evaluate the impact of the location of a projected PHA production plant on economic viability and process sustainability. The energy supply aspect is crucial since the rendering process used industrially for lipid recovery from the waste streams displays an exceedingly energy-consuming step; consequently, the energy mix (fossil, renewable, nuclear) prevailing in different global regions massively dictates the ecological footprint of the ANIMPOL-based PHA-production process resorting to animal residues. As a general suggestion, the authors concluded that transport routes for raw materials to the PHA production plant have to be as short as possible in order to achieve the highest possible profitability. As the most decisive result of the study, the authors identified a range of ecological footprint, expressed as surface area needed to produce one $\mathrm{PHA}$, between $373,000 \mathrm{~m}^{2}$ for the production plant being located in Norway (more than $90 \%$ of energy produced by hydropower) and $956,000 \mathrm{~m}^{2}$ for a plant operated in France (high share of nuclear energy in the usual energy mix); these footprint values are significantly lower than previously published results assessing the environmental impact of $\mathrm{PE}$, which amounts to about $2.500,000 \mathrm{~m}^{2}$ (92).

Later, Narodoslawsky and colleagues studied different other factors that influence the environmental impact of the ANIMPOL process and other biorefinery-like PHA production processes resorting to inexpensive substrates. Inter alia, co-substrate supplementation, downstream processing for PHA separation from cells, etc., were considered. Modern tools to calculate the ecological footprint of biopolymers were applied in this study, such as the well-established sustainable process index (SPI). As major conclusion, the authors underline that PHA- or biopolymer production in general is not per se of higher sustainability than production of traditional full-carbon-backbone polymers from fossil resources; however, it was emphasized that PHA production can become ecologically superior, provided that all process steps (selection and pre-treatment of raw materials, bioengineering, downstream processing, energy source, closing of material-, water-, and energy cycles) are taken into account and optimized (102).

Only recently, a comprehensive economic study for the ANIMPOL biorefinery concept including the utilization of additional fractions of the animal processing was accomplished by Shahzad and colleagues. This study covers the utilization of SFAE (biodiesel of low-quality) as main substrate, and hydro- 
lyzed innards as complex nitrogen source; in this calculation, current market values for MBM (use as fertilizer) and the unsaturated FAME fraction (use as biofuel) are considered, showing that these fractions should not undergo bioconversion, but should rather be sold to create more value for the overall process. The techno-economic analysis presented in this study showed that PHA production cost fluctuates between $1.41 € / \mathrm{kg}$ and $1.64 € / \mathrm{kg}$ depending on whether one considers the innards as a waste stream, or if their market value is considered; for unsaturated FAME fraction (sold as biodiesel) and MBM, fixed costs of $0.97 € / L$ and $350 € / t$, respectively, were used for cost-accounting. The impact of market value fluctuations for biodiesel, MBM, and innards, on the final PHA production price, and the return of investment time were determined. The most important result was that, depending on the current market situation, return of investment time for a plant generating 10,000 annual tons of PHA varies between 3.25 and 4.5 years (24).

\section{Conclusions}

The present article demonstrates that the production of PHA biopolyesters is complex, and particular steps in the production chain must be taken into account to make the manufacturing process on an industrial scale both economical and sustainable. The upgrading of a wide variety of high-carbon waste streams from a variety of industries will provide these companies with the opportunity to make sustainable use of their waste streams, while helping to reduce the current environmental impact of these industrial wastes. In addition, food and feed reserves can be saved because nutritionally relevant raw materials that were previously used for biopolyester production no longer have to be used for this purpose. In addition, it should be kept in mind that many of these carbon-rich waste streams occur in those parts of the world where the labor market situation is considerably strained. The integration of biopolyester production into production lines of such companies, where the raw materials (whey, low quality biodiesel, crude glycerol, lignocelluloses, etc.) are directly generated as a waste stream, could have a positive effect on the labor market situation in many eco-socially disadvantaged areas. In order not to contradict the noble pattern of sustainability of the entire biopolyester production process, special attention must be paid not only to the raw material issue, but also to the downstream processing technique. This requires that such sustainable and novel PHA recovery methods, which have already delivered excellent results on a laboratory scale, must finally be scaled up to test their industrial applicability. In summary, the synergistic collaboration of diverse scientific disciplines, as well as the close interaction between academia and industry, is required to successfully manage the long-awaited transfer of lab results to industrial maturity. This transfer must necessarily be based on the principles of "Cleaner Production", "Zero Emmission", and "Zero Waste" in order to be able to produce biopolyesters as promising materials in the most sustainable way possible.

\section{Acknowledgements}

The authors gratefully acknowledges the financial support provided by the European Commission by granting the collaborative R\&D projects WHEYPOL ("Dairy industry waste as source for sustainable polymeric material production"; G5RD-CT-2001-00591) and ANIMPOL ("Biotechnological Conversion of Carbon Containing Wastes for Eco-Efficient Production of High-Value Products"; project nr. 245084).

\section{Conflict of interest statement}

The authors declare no conflict of interest.

\section{References}

1. Geyer R, Jambeck JR, Law KL. Production, use, and fate of all plastics ever made. Sci Adv 2017; 3(7): e1700782.

2. Online resource 1: www.plasticseurope.org. last access April $6^{\text {th }}$, 2018

3. Singh N, Hui D, Singh R, Ahuja IPS, Feo L, Fraternali F. Recycling of plastic solid waste: A state of art review and future applications. Composites Part B: Engineering 2017; 115: 409-422.

4. Lebreton LC, Van der Zwet J, Damsteeg JW, Slat B, Andrady A, Reisser J. River plastic emissions to the world's oceans. Nat Comm 2017; 8: 15611.

5. Braunegg G, Bona R, Koller M. Sustainable polymer production. Polym-Plast Technol Eng 2004; 43(6): 1779-1793.

6. Koller M, Maršálek L, Miranda de Sousa Dias M, Braunegg G. Producing microbial polyhydroxyalkanoate (PHA) biopolyesters in a sustainable manner. New Biotechnol 2017; 37(A): 24-38.

7. Kourmentza C, Plácido J, Venetsaneas N, Burniol-Figols A, Varrone C, Gavala HN, Reis MAM. Recent advances and challenges towards sustainable polyhydroxyalkanoate (PHA) production. Bioengineering 2017; 4(2): 55.

8. Lemoigne M. Produits de deshydration et de polymerisation de l'acide $\beta$ - oxybutyrique. Bull Soc Chim Biol 1926; 8: 770-782.

9. Obruca S, Sedlacek P, Koller M, Kucera D, Pernicova I. Involvement of polyhydroxyalkanoates in stress resistance of microbial cells: Biotechnological consequences and applications. Biotechnol Adv 2018 (online ahead of print; doi: 10.1016/j.biotechadv.2017.12.006.

10. Obruca S, Marova I, Stankova M, Mravcova L, Svoboda Z. Effect of ethanol and hydrogen peroxide on poly (3-hydroxybutyrate) biosynthetic pathway in Cupriavidus necator H16. World J Microbiol Biotechnol 2010; 26(7): 1261-1267.

11. Obruca S, Sedlacek P, Mravec F, Samek O, Marova I. Evaluation of 3-hydroxybutyrate as an enzyme-protective agent against heating and oxidative damage and its potential role in stress response of poly (3-hydroxybutyrate) accumulating cells. Appl Microbiol Biotechnol 2016; 100(3): 1365-1376.

12. Obruca S, Sedlacek P, Mravec F. Krzyzanek V, Nebesarova J, Samek $\mathrm{O}$, et al. The presence of PHB granules in cytoplasm protects non-halophilic bacterial cells against the harmful impact of hypertonic environments. New Biotechnol 2017; 39: 68-80.

13. Slaninova E, Sedlacek P, Mravec F, Mullerova L, Samek O, Koller $\mathrm{M}$, et al. Light scattering on PHA granules protects bacterial cells against the harmful effects of UV radiation. Appl Microbiol Biotechnol 2018; 102(4): 1923-1931.

14. Obruca S, Sedlacek P, Krzyzanek V, Mravec F, Hrubanova K, Samek $\mathrm{O}$, et al. Accumulation of poly (3-hydroxybutyrate) helps bacterial cells to survive freezing. PloS one 2016; 11(6): e0157778.

15. Jiang G, Hill DJ, Kowalczuk M, Johnston B, Adamus G, Irorere V, Radecka I. Carbon sources for polyhydroxyalkanoates and an integrated biorefinery. Int J Mol Sci 2016; 17(7): 1157.

16. Dietrich K, Dumont MJ, Del Rio LF, Orsat V. Producing PHAs in the 
bioeconomy-Towards a sustainable bioplastic. Sust Prod Consum 2017; 9: 58-70.

17. Koller M, Sandholzer D, Salerno A, Braunegg G, Narodoslawsky M. Biopolymer from industrial residues: Life cycle assessment of poly (hydroxyalkanoates) from whey. Res Cons Recyc 2013; 73: 64-71.

18. Obruca S, Benesova P, Marsalek L, Marova I. Use of lignocellulosic materials for PHA production. Chem Biochem Eng Q 2015; 29(2): 135-144.

19. Albuquerque MGE, Eiroa M, Torres C, Nunes BR, Reis MAM. Strategies for the development of a side stream process for polyhydroxyalkanoate (PHA) production from sugar cane molasses. $J$ Biotechnol 2007; 130: 411-421.

20. Queirós D, Rossetti S, Serafim LS. PHA production by mixed cultures: a way to valorize wastes from pulp industry. Biores Technol 2014; 157: 197-205.

21. Pittmann T, Steinmetz H. Polyhydroxyalkanoate production on waste water treatment plants: Process scheme, operating conditions and potential analysis for German and European municipal waste water treatment plants. Bioengineering 2017; 4(2): 54.

22. Kourmentza C, Koutra E, Venetsaneas N, Kornaros M. Integrated biorefinery approach for the valorization of olive mill waste streams towards sustainable biofuels and bio-based products. In: Microbial Applications Vol. 1; 2017, pp. 211-238, Springer, Cham.

23. Troschl C, Meixner K, Drosg B. Cyanobacterial PHA productionReview of recent advances and a summary of three years' working experience running a pilot plant. Bioengineering 2017: 4(2): 26.

24. Shahzad K, Narodoslawsky M, Sagir M, Ali N, Ali S, Rashid Ml, et al. Techno-economic feasibility of waste biorefinery: Using slaughtering waste streams as starting material for biopolyester production. Waste Manage 2017; 67: 73-85.

25. Koller M, Niebelschütz $H$, Braunegg $G$. Strategies for recovery and purification of poly $[(R)-3$-hydroxyalkanoates)(PHA) biopolyesters from surrounding biomass. Eng Life Sci 2013; 13(6): 549-562.

26. Kosseva MR, Rusbandi E. Trends in the biomanufacture of polyhydroxyalkanoates with focus on downstream processing. Int J Biol Macromolecul 2018; 107(A): 762-778

27. Madkour MH, Heinrich D, Alghamdi MA, Shabbaj II, Steinbüchel A. PHA recovery from biomass. Biomacromolecules 2013; 14(9): 2963-2972.

28. Koller M, Bona R, Chiellini E, Braunegg G. Extraction of shortchain-length poly-[(R)-hydroxyalkanoates] (scl-PHA) by the "anti-solvent" acetone under elevated temperature and pressure. Biotechnol Lett 2013; 35(7): 1023-1028.

29. Daly SR, Fathi A, Bahramian B, Manavitehrani I, McClure DD, Valtchev $P$, et al. A green process for the purification of biodegradable poly( $\beta$-hydroxybutyrate). J Supercrit Fluids 2018; 135: 84-90.

30. Dubey S, Bharmoria P, Gehlot PS, Agrawal V, Kumar A, Mishra S. 1-Ethyl-3-methylimidazolium diethylphosphate based extraction of bioplastic "Polyhydroxyalkanoates" from bacteria: Green and Sustainable Approach. ACS Sust Chem Eng 2017; 6(1): 766-773.

31. Ong SY, Zainab-L I, Pyary S, Sudesh K. A novel biological recovery approach for PHA employing selective digestion of bacterial biomass in animals. Appl Microbiol Biotechnol 2018; 122(5): 2117-2127.

32. Hsiao LJ, Lee MC, Chuang PJ, Kuo YY, Lin JH, Wu TM, Li SY. The production of poly (3-hydroxybutyrate) by thermophilic Caldimonas manganoxidans from glycerol. J Polym Res 2018; 25(4): 85.

33. Koller M. Production of Polyhydroxyalkanoate (PHA) Biopolyesters by Extremophiles. MOJ Polym Sci 2017; 1(2): 1-19.

34. Kucera D, Pernicová I, Kovalcik A, Koller M, Mullerova L, Sedlacek P, et al. Characterization of the promising poly (3-hydroxybutyrate) producing halophilic bacterium Halomonas halophila. Biores Technol 2018; 256: 552-556.

35. Rodriguez-Contreras A, Koller M, Braunegg G, Marqués-Calvo MS. Poly[(R)-3-hydroxybutyrate] production under different salinity conditions by a novel Bacillus megaterium strain. New Biotechnol 2016; 33(1): 73-77.

36. Chen GQ, Hajnal I. The 'PHAome'. Trends Biotechnol 2015; 33(10): 559-564.

37. Rodriguez-Perez S, Serrano A, Pantión AA, Alonso-Fariñas B. Challenges of scaling-up PHA production from waste streams. A review. J Environ Manage 2018; 205: 215-230.

38. Kaur G, Roy I. Strategies for large-scale production of polyhydroxyalkanoates. Chem Biochem Eng Q 2015; 29(2): 157-172.

39. Koller M, Bona R, Braunegg G, Hermann C, Horvat P, Kroutil M, et al. Production of polyhydroxyalkanoates from agricultural waste and surplus materials. Biomacromolecules 2005; 6(2): 561-565.

40. Braunegg G, Genser K, Bona R, Haage G, Schellauf F, Winkler E. Production of PHAs from agricultural waste material. Macromol Symp 1999; 144(1): 375-383.

41. Moita R, Freches A, Lemos PC. Crude glycerol as feedstock for polyhydroxyalkanoates production by mixed microbial cultures. Water Res 2014; 58: 9-20.

42. Perez Amaro L, Abdelwahab MA, Morelli A, Chiellini F, Chiellini E. Bacterial polyesters: The issue of their market acceptance and potential solutions. In: Koller M. (Ed.), Recent Advances in Biotechnology, 2016, Vol. 2, pp. 3-74; Bentham Science Publishers

43. Koller M, Bona R, Hermann C, Horvat P, Martinz J, Neto J, et al. Biotechnological production of poly(3-hydroxybutyrate) with Wautersia eutropha by application of green grass juice and silage juice as additional complex substrates. Biocat Biotrans 2005; 23(5): 329337.

44. Obruca S, Benesova P, Marsalek L, Marova I. Use of lignocellulosic materials for PHA production. Chem Biochem Eng Q 2015; 29(2): 135-144.

45. Ahn WS, Park SJ, Lee SY. Production of poly(3-hydroxybutyrate) by fed-batch culture of recombinant Escherichia coli with a highly concentrated whey solution. Appl Environ Microbiol 2000; 66: 3624-3627.

46. Koller M, Salerno A, Muhr A, Reiterer A, Chiellini E, Casella S, et al. Chapter 2: Whey lactose as a raw material for microbial production of biodegradable polyester. In: Saleh HE-DM (Ed.). Polyesters. InTech, Rijeka; 2012, pp.19-60.

47. Ahn WS, Park SJ, Lee SY. Production of poly(3-hydroxybutyrate) from whey by cell recycle fed-batch culture of recombinant Escherichia coli. Biotechnol Lett 2001; 23: 235-240.

48. Haas C, El-Najjar T, Virgolini N, Smerilli M, Neureiter M. High cell-density production of poly(3-hydroxybutyrate) in a membrane bioreactor. New Biotechnol 2017; 37: 117-122.

49. Kucera D, Benesova P, Ladicky P, Pekar M, Sedlacek P, Obruca S. Production of polyhydroxyalkanoates using hydrolyzates of spruce sawdust: Comparison of hydrolyzates detoxification by application of overliming, active carbon, and lignite. Bioengineering 2017: 4(2): 53.

50. Silva LF, Taciro MK, Ramos MM, Carter JM, Pradella JGC, Gomez JGC. Poly-3-hydroxybutyrate (P3HB) production by bacteria from xylose, glucose and sugarcane bagasse hydrolysate. J Ind Microbiol Biot 2004; 31(6): 245-254

51. Haas C, Steinwandter V, Diaz De Apodaca E, Maestro Madurga B, Smerilli M, Dietrich T, et al. Production of PHB from chicory rootscomparison of three Cupriavidus necator strains. Chem Biochem Eng Q 2015; 29(2): 99-112

52. Hájek M, Skopal F, Čapek L, Černoch M, Kutálek P. Ethanolysis of rapeseed oil by $\mathrm{KOH}$ as homogeneous and as heterogeneous catalyst supported on alumina and CaO. Energy 2012; 48(1):392-397.

53. Xiao $Y$, Xiao G, Varma A. A universal procedure for crude glycerol purification from different feedstocks in biodiesel production: experimental and simulation study. Ind Eng Chem Res 2013; 52(39): 14291-14296.

54. Koncar M, Mittelbach M, Gössler H, Hammer W. Catalytic trans- 
esterification of a triglycerides and fatty acids. U.S. Patent No. 6,696,583, 24 Feb. 2004.

55. Skopal F, Komers K, Machek J. A new method of dealcoholization of crude biodiesel fuel. Lipid/Fett 1997;99(3):87-90.

56. Moita R, Freches A, Lemos PC. Crude glycerol as feedstock for polyhydroxyalkanoates production by mixed microbial cultures. Water Res 2014; 58: 9-20.

57. Ward PG, Goff M, Donner M, Kaminsky W, O'Connor KE. A two step chemo-biotechnological conversion of polystyrene to a biodegradable thermoplastic. Environ Sci Technol 2006; 40(7): 24332437.

58. Johnston B, Jiang G, Hill D, Adamus G, Kwiecień I, Zięba M, et al. The molecular level characterization of biodegradable polymers originated from polyethylene using non-oxygenated polyethylene wax as a carbon source for polyhydroxyalkanoate production. Bioengineering 2017; 4(3): 73.

59. Guimarães PMR, Teixeira JA, Domingues L. Fermentation of lactose to bio-ethanol by yeasts as part of integrated solutions for the valorisation of cheese whey. Biotechnol Adv 2010; 28(3): 37584.

60. Kosikowski FV. Whey utilisation and whey products. J Dairy Sci 1979; 62: 1149-60.

61. Illanes A. Whey upgrading by enzyme biocatalysis. Electron J Biotechnol 2011; 14(6): 15.

62. Ghaley AE, El-Taweel AA. Kinetic modelling of continuous production of ethanol from cheese whey. Biomass Bioenerg 1997; 12(6): 461-472.

63. Aneja RP, Mathur BN, Chandan RC, Banerjee AK. Technology of Indian milk products: Handbook on process technology modernization for professionals, entrepreneurs and scientists. Dairy India Yearbook 2002.

64. Corgneau M, Scher J, Ritie-Pertusa L, Le D, Petit, J, Nikolova Y, et al. Recent advances on lactose intolerance: Tolerance thresholds and currently available answers. Crit Rev Food Sci Nutr 2017; 57(15): 3344-3356.

65. Viñas M, Borzacconi L, Martínez J. Anaerobic treatment of yeast manufacturing wastewater in UASB reactors. Environ Technol 1994; 15: 79-85.

66. Gonzales Siso MI. The biotechnological utilization of cheese whey: A review. Bioresource Technol 1996; 57: 1-11.

67. Koller M, Marsalek L, Braunegg G. PHA Biopolyester production from surplus whey: microbiological and engineering aspects. In: Koller M. (Ed.), Recent Advances in Biotechnology, 2016, Vol. 1, pp. 100-174, Bentham Science Publishers.

68. Koller M, Hesse P, Bona R, Kutschera C, Atlić A, Braunegg G. Potential of various archae-and eubacterial strains as industrial polyhydroxyalkanoate producers from whey. Macromol Biosci 2007; 7(2): 218-226.

69. Koller M, Bona R, Chiellini E, Fernandes EG, Horvat P, Kutscher C., et al. Polyhydroxyalkanoate production from whey by Pseudomonas hydrogenovora. Biores Technol 2008; 99(11): 4854-4863.

70. Koller M, Atlić A, Gonzalez-Garcia Y, Kutschera C, Braunegg G. Polyhydroxyalkanoate (PHA) biosynthesis from whey lactose. Macromol Symp 2008; 272(1): 87-92).

71. Han J, Hou J, Zhang F, Ai G, Li M, Cai S, et al. Multiple propionyl coenzyme A-supplying pathways for production of the bioplastic poly (3-hydroxybutyrate-co-3-hydroxyvalerate) in Haloferax mediterranei. Appl Environ Microbiol 2013; 79(9): 2922-2931.

72. Koller M. Recycling of waste streams of the biotechnological poly (hydroxyalkanoate) production by Haloferax mediterranei on whey. Int J Polym Sci 2015; 2015: article ID 370164

73. Pais J, Serafim LS, Freitas F, Reis MAM. Conversion of cheese whey into poly(3-hydroxybutyrate-co-3-hydroxyvalerate) by Haloferax mediterranei. New Biotechnol 2015; 33(1): 224-30.

74. Hermann-Krauss C, Koller M, Muhr A, Fasl H, Stelzer F, Braunegg G.
Archaeal production of polyhydroxyalkanoate (PHA) co-and terpolyesters from biodiesel industry-derived by-products. Archaea 2013; 2013: article ID 129268.

75. Huang TY, Duan KJ, Huang SY, Chen CW. Production of polyhydroxyalkanoates from inexpensive extruded rice bran and starch by Haloferax mediterranei. J Ind Microbiol Biotechnol 2006; 33(8): 701-6.

76. Chen CW, Don TM, Yen HF. Enzymatic extruded starch as a carbon source for the production of poly (3-hydroxybutyrate-co-3-hydroxyvalerate) by Haloferax mediterranei. Process Biochem 2006; 41(11): 2289-96.

77. Alsafadi D, Al-Mashaqbeh O. A one-stage cultivation process for the production of poly-3-(hydroxybutyrate-co-hydroxyvalerate) from olive mill wastewater by Haloferax mediterranei. New biotechnol 2017; 34: 47-53.

78. Obruca S, Marova I, Melusova S, Mravcova L. Production of polyhydroxyalkanoates from cheese whey employing Bacillus megaterium CCM 2037. Ann Microbiol 2011; 61(4): 947-953.

79. Koller M, Puppi D, Chiellini F, Braunegg G. Comparing chemical and enzymatic Hydrolysis of whey lactose to generate feedstocks for haloarchaeal poly(3-hydroxybutyrate-co-3-hydroxyvalerate) biosynthesis. Int J Pharm Sci Res 2016; 3(1).

80. Obruca S, Benesova P, Oborna J, Marova I. Application of protease-hydrolyzed whey as a complex nitrogen source to increase poly(3-hydroxybutyrate) production from oils by Cupriavidus necator. Biotechnol Lett 2014; 36(4): 775-781.

81. Koller M. Poly(hydroxyalkanoates) for food packaging: Application and attempts towards implementation. App Food Biotechnol 2014; 1(1): 3-15.

82. Cinelli P, Schmid M, Bugnicourt E, et al. Whey protein layer applied on biodegradable packaging film to improve barrier properties while maintaining biodegradability. Polym Degrad Stabil 2014; 108: 151-7.

83. Koller M, Braunegg G. Biomediated production of structurally diverse poly(hydroxyalkanoates) from surplus streams of the animal processing industry. Polimery 2015;60:298-308. doi:10.14314/ polimery.2015.298

84. Online resource 2: http://cordis.europa.eu/result/rcn/58861_ en.html (last accessed April 13 $3^{\text {th }}, 2018$ )

85. Ebringer A. The problem of Bovine Spongiform Encephalopathy also known as "mad cow disease" in the United Kingdom. In: Multiple sclerosis, mad cow disease and Acinetobacter, 2015, pp. 1520. Springer, Cham.

86. Schober S, Seidl I, Mittelbach M. Ester content evaluation in biodiesel from animal fats and lauric oils. Europ J Lipid Sci Technol. 2006; 108: 309-314.

87. Koller M, Maršálek L. Principles of glycerol-based Polyhydroxyalkanoate (PHA) production. Appl Food Biotechnol. 2015; 2(4): 3-10.

88. Koller M, Maršalek L. Potential of diverse prokaryotic organisms for glycerol-based Polyhydroxyalkanoate production. Appl Food Biotechnol. 2015; 2(3): 3-15.

89. Špoljarić IV, Lopar M, Koller, M., Muhr A, Salerno A, Reiterer A, Horvat P. In silico optimization and low structured kinetic model of poly[(R)-3-hydroxybutyrate] synthesis by Cupriavidus necator DSM 545 by fed-batch cultivation on glycerol. J Biotechnol. 2013; 168: 625-635.

90. Koller M, Salerno A, Muhr A, Reiterer A, Braunegg G. Polyhydroxyalkanoates: Biodegradable polymers and plastics from renewable resources. Mater Tehnol. 2013; 47: 5-12.

91. Titz M, Kettl KH, Shahzad K, Koller M, Schnitzer H, Narodoslawsky M. Process optimization for efficient biomediated PHA production from animal-based waste streams. Clean Technol Environ Pol. 2012; 14: 495-503.

92. Shahzad K, Kettl KH, Titz M, Koller M, Schnitzer H, Narodoslawsky M. Comparison of ecological footprint for biobased PHA produc- 
tion from animal residues utilizing different energy resources. Clean Technol Environ Pol. 2013; 15: 525-536.

93. Cromwick AM, Foglia T, Lenz RW. The microbial production of poly (hydroxyalkanoates) from tallow. Appl Microbiol Biotechnol. 1996; 46: 464-469.

94. Ashby RD, Foglia TA. Poly(hydroxyalkanoate) biosynthesis from triglyceride substrates. Appl Microbiol Biotechnol. 1998; 49: 431437.

95. Nonato R, Mantelatto P, Rossell C. Integrated production of biodegradable plastic, sugar and ethanol. Appl Microbiol Biotechnol. 2001; 57(1-2): 1-5.

96. Koller M, Salerno A, Strohmeier K, Schober S, Mittelbach M, Illieva $V$, Chiellini E, Braunegg $G$. Novel precursors for production of 3-hydroxyvalerate-containing poly[(R)-hydroxyalkanoate]s. Biocat Biotrans. 2014; 32: 161-167.

97. Muhr A, Rechberger EM, Salerno A, Reiterer A, Schiller M, Kwiecien M, Adamus G, Kowalczuk M, Strohmeier K, Schober S, Mittelbach $\mathrm{M}$, Koller M. Biodegradable latexes from animal-derived waste: $\mathrm{Bi}$ - osynthesis and characterization of $\mathrm{mcl}-\mathrm{PHA}$ accumulated by Ps. citronellolis. React Funct Polym. 2013; 73: 1391-1398.

98. Muhr A, Rechberger, EM, Salerno A, Reiterer A, Malli K, Strohmeier K, Schober S, Mittelbach M, Koller M. Novel description of $\mathrm{mcl}^{-}$ PHA biosynthesis by Pseudomonas chlororaphis from animal-derived waste. J Biotechnol. 2013; 165: 45-51.

99. Riedel SL, Jahns S, Koenig S, Bock MC, Brigham CJ, Bader J, Stahl U. Polyhydroxyalkanoates production with Ralstonia eutropha from low quality waste animal fats. J Biotechnol. 2015; 214: 119-127.

100. Kettl K-H, Titz M, Koller M, Shahzad K, Schnitzer H, Narodoslawsky $M$. Process design and evaluation of biobased polyhydroxyalkanoates (PHA) production. Chem Eng Trans. 2011; 25: 983-988

101. Schnitzer $\mathrm{H}$, Ulgiati $\mathrm{S}$. Less bad is not good enough: approaching zero emissions techniques and systems. J Cleaner Prod. 2007; 15: 1185-1189.

102. Narodoslawsky M, Shahzad K, Kollmann R, Schnitzer H. LCA of PHA production-identifying the ecological potential of bio-plastic. Chem Biochem Eng Q. 2015; 29: 299-305. 